\title{
Toll-Like Receptor Signaling and Regulation of Cytokine Gene Expression in the Immune System
}

\author{
Keiko Ozato, Hideki Tsujimura, and Tomohiko Tamura \\ National Institute of Child Health and Human Development, National Institutes of Health, Bethesda, MD, USA
}

BioTechniques 33:S66-S75 (October 2002)

\section{ABSTRACT}

Dendritic cells, macrophages, and granulocytes are derived from hematopoietic stem cells and provide a first line of defense against infectious pathogens. Toll-like receptors (TLRs) expressed on these cells recognize molecular structures present in the pathogens. Upon binding of a pathogen ligand, TLRs trigger a cascade of signaling pathways that is conserved from insect to plants to humans, which ultimately activates $N F K B$. In mammalian cells, this leads to the induction of cytokine genes and the establishment of innate immunity. For example, TLR signals induce type I interferons (IFN $\alpha \beta$ ) in dendritic cells conferring an antiviral state upon host cells. Moreover, TLR signals stimulate not only pro-inflammatory cytokines such as IFNs, IL-1, $T N F \alpha$, and IL-12 but also anti-inflammatory cytokines such as $I L-10$ and IL-6. IL-12 and IL-10 are cytokines that bridge early innate responses and the ensuing specific immune responses. TLR signals also enhance an antigen presentation capacity in dendritic cells and macrophages. Recent studies with mouse and human cells indicate that TLRs activate multiple signaling cascades that involve chromatin structure alterations as well as activation of many transcription factors (e.g., IRF-3, IRF-8/ICSBP, and PU.1). Together, although the basic backbone is conserved throughout evolution, the TLR signaling system in mammalian species has an added complexity to accommodate a mechanism that links innate and adaptive immunity.

\section{THE TOLL-LIKE RECEPTOR SYSTEM}

Toll-like receptors (TLRs) are transmembrane molecules that contain a leucine-rich repeat motif in the external domain. In mammalian species, there are 10 TLRs, which are structurally similar to the IL-1 receptor and IL-18 receptor in the TIR domain, although the external domain is divergent $(28,31,57)$. The TLR system is conserved throughout evolution, and similar receptors and signaling pathways are present in insects and plants $(37,57)$. The conservation of the TLRs is likely to be attributed to their critical role in host defense, although TLRs in Drosophila play an important role in early development as well (37).

Table 1 lists the ligands identified for each TLR, showing that TLRs recognize a diverse set of ligands with a high level of specificity. TLR4, the best-studied TLR, recognizes bacterial lipopolysaccharides (LPSs) whose active moiety is lipid A. The
TLR4 gene is mutated in the mouse strains $\mathrm{C} 3 \mathrm{H} / \mathrm{HeJ}$ and $\mathrm{C} 57 \mathrm{~B} / 10 \mathrm{ScCr}$ that fail to respond to LPS [i.e., they are resistant to LPS-mediated endotoxin shock and are susceptible to infection by Gram-negative bacteria (61)]. A later study showed that TLR4-/- mice exhibit basically the same phenotype as C3H/HeJ (27). TLR4-/- and C3H/HeJ mice do not express TNF $\alpha$, IL-6, and IL-12 in response to LPS, although these mice are capable of producing the cytokines in response to the TLR2 ligands.

Interestingly, TLRs can recognize not only membrane components of pathogens but also nucleic acids. TLR3 and TLR9 recognize dsRNA and unmethylated CpG DNA, respectively. It is known that CpG DNA from bacterial sources are largely unmethylated and elicit strong inflammatory responses that induce many cytokines, such as IL-12 and IL-10 (38). On the other hand, CpG DNA in the mammalian genomes are highly methylated, evading TLR recognition. TLR9 recognition of unmethylated CpG DNA was verified by the analysis of TLR9-/- mice and "gain of function" experiments $(6,23)$. While TLR9-/- cells fail to induce cytokines in response to CpG (but not to LPS or PGN), transfection of TLR9 confers responsiveness to CpG. Analysis of TLR3-/- mice (2) and a study with cells transfected with TLR3 (50) established that this receptor recognizes dsRNA. Illustrating specificity for dsRNA, neither DNA nor ssRNA is recognized by TLR3.

In the event of infection, multiple TLRs simultaneously engage in ligand recognition, potentially generating complex downstream pathways. How different TLRs affect each other's activity upon ligand engagement is not fully understood. Simplistically, a certain degree of synergy may be expected among different TLRs. Indeed TLR2 and TLR4 are shown to synergize when two respective ligands are added together (68). However, the mechanism by which TLRs can recognize diverse molecular structures is currently unknown.

\section{REGULATION OF TLR EXPRESSION}

Among the major cell types that express TLRs, granulocytes and macrophages are derived from a common myeloid progenitor. The two cell types develop through an intrinsic mechanism 
Table 1. Mammalian TLRs

\begin{tabular}{|c|c|c|c|}
\hline TLR & Ligand & Pathogen & Reference \\
\hline TLR 1 & Lipopeptides & Mycobacteria & 74 \\
\hline \multirow[t]{3}{*}{ TLR 2} & Lipoproteins & $\begin{array}{l}\text { Gram-positive } \\
\text { Bacteria }\end{array}$ & 73,84 \\
\hline & Zymosan & Yeast & \\
\hline & $\begin{array}{l}\text { Lipoarabino- } \\
\text { mannan }\end{array}$ & Mycobacteria & \\
\hline TLR3 & Ds RNA & $\begin{array}{l}\text { RNA and DNA } \\
\text { Viruses }\end{array}$ & 2 \\
\hline TLR4 & LPS & $\begin{array}{c}\text { Gram-negative } \\
\text { Bacteria }\end{array}$ & $27,61,63$ \\
\hline TLR5 & Flagellin & Bacteria & 21 \\
\hline TLR6 & $\begin{array}{l}\text { Peptidoglycan } \\
\text { Lipopeptides }\end{array}$ & Mycoplasma & 59 \\
\hline TLR7 & Imidazoquinolin & & 22 \\
\hline TLR8 & Imidazoquinolin & $?$ & 29 \\
\hline TLR9 & $\begin{array}{l}\text { Unmethylated } \\
\text { CpG DNA }\end{array}$ & Bacteria & 6,23 \\
\hline TLR10 & $?$ & $?$ & \\
\hline
\end{tabular}

involving the activity of specific transcription factors including IRF-8/ICSBP, PU.1, and C/EBP, although cytokines such as MCSF and G-CSF influence the course of their development $(75,76)$. In the adult bone marrow, the pro-inflammatory cytokine IFN $\gamma$ influences myeloid development, favoring macrophage differentiation in a IRF-8/ICSBP-dependent manner (81). Dendritic cells are the most efficient cells that produce

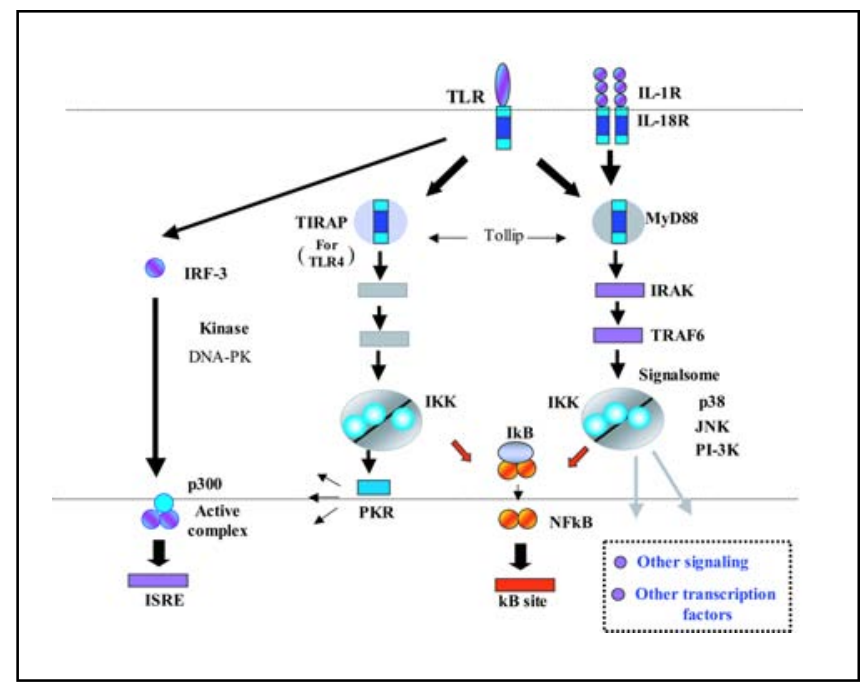

Figure 1. TLR signaling pathway. Ligand-bound TLRs recruit the adaptor MyD88 and transmit signals through the activation of a series of kinases. In addition to MyD88, TLR4 utilizes another adaptor, TIRAP. Both TIRAP and MyD88 pathways result in the activation of NFKB. TLR4 also activates IRF-3 through a MyD88-independent mechanism. cytokines in response to TLR signaling (5). Recent evidence indicates that IRF-8/ICSBP plays an important role in dendritic cell development (82).

At present, developmental regulation of the TLR genes (and genes for TLR signaling) is not well delineated, although it is likely to be an important part of the growth and differentiation of dendritic cells and macrophages. Nevertheless, in light of the observations that TLR-deficient mice are born normal and fertile in pathogen-free conditions, mammalian TLRs are apparently not critical for early development. TLR4 expression is shown to be regulated by IRF-8/ICSBP and PU.1 (64), both transcription factors critical for myeloid and dendritic cell development. TLR ligand binding is central to the maturation of dendritic cells. Upon ligand binding, immature dendritic cells express costimulatory molecules at higher levels and gain a higher antigen presentation capacity, which coincides with the induction of a series of cytokines. In humans, different dendritic cell subsets express TLRs at different levels and respond to different microbes. Accordingly, they produce cytokines at different levels $(26,85)$. While "plasmacytoid" dendritic cells (pDCs) produce a large amount of IFN $\alpha / \beta$, "monocyte" (or myeloid) dendritic cells (mDCs) predominantly manufacture IL-12 $(13,30)$.

TLR expression by dendritic cells is transiently increased following ligand addition both in humans and mice (85). In monocytes and macrophages, LPS enhances the expression of TLR4 (55) and TLR9 (2). Thus, TLR expression is stimulated by their respective ligands in these cells. However, prolonged ligand engagement results in ligand-specific negative regulation of receptor expression, as reported for CpG and LPS $(26,51)$. Thus, ligand binding may cause different modes of regulation in TLR expression, depending on the stage of cell maturation. TLR expression in macrophages is markedly enhanced by IFN $\gamma$, as documented for TLR4 and other TLRs $(8,22)$. This up-regulation provides an explanation for the long-acknowledged "priming effect" of IFN $\gamma$ on macrophages $(43,72)$.

\section{TLR SIGNALING PATHWAYS}

A rough outline of the TLR signaling pathway has been described in both mammals and Drosophila. It is clear that the backbone of the pathway is conserved throughout evolution $(28,31,37,57)$. Fundamental to this process is the activation of $\mathrm{NFKB}$, the endpoint of TLR signaling (Figure 1). However, mammalian species clearly have added complexities at various step of signaling (see below).

Upon ligand binding, TLR 4 complexes with the cytoplasmic adaptor protein MyD88. Discovered as a gene expressed during myeloid cell differentiation (41), MyD88 has a TIR domain similar to that of TLRs in the C-terminal domain, but it does not have the external domain present in TLRs. The TLR-MyD88 complex recruits IRAK (90) and then TRAF6 (12). It is then complexed with the signalsome, a multi-protein complex that activates IKK (56) and p38 MAPK plus MEKK (57). This results in the activation of NFKB (and presumably AP-1) $(31,57)$.

The importance of MyD88 in TLR signaling was confirmed by the finding that MyD88-/- mice fail to induce cytokines in response to LPS and CpG (34). MyD88 is required for signaling not only by TLRs but also by IL-1R and IL-18R, as 


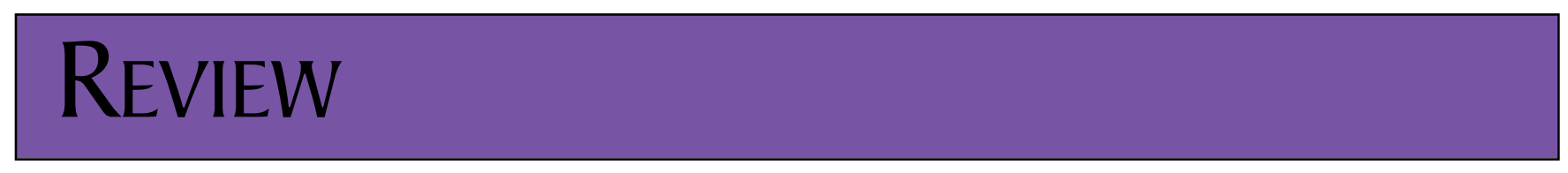

MyD88-/- cells do not respond to IL-1 and IL-18 (1). When IKK is activated, it phosphorylates I $\mathrm{B}$, a cytoplasmic molecule

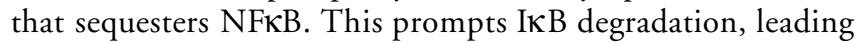
to the activation of $\mathrm{NF \kappa B}$ and the transcription of numerous genes involved in inflammatory responses. It is notable that MyD88 is not indispensable for LPS-mediated signaling, as evidenced by the activation, albeit delayed, of NFKB and MAPK in MyD88-/- mice (32,35).

TIRAP (also called Mal) is another adaptor recruited to TLR4 and that takes part in LPS signaling $(17,25)$. TIRAP has a nonredundant function, as LPS induction of IFN $\beta$ is dependent on TIRAP, but not on MyD88 (79). TIRAP also activates PKR, a kinase with antiviral activities. Another adaptor protein (Tollip) that also interacts with TLRs was recently reported (93). Tollip appears to negatively affect TLR signaling, possibly by limiting inflammatory responses.

By screening LPS-inducible genes in MyD88-/- macrophages, Kawai et al. (35) identified a MyD88-independent pathway downstream of TLR4. This pathway activates IRF-3, a latent cytoplasmic factor, which is phosphorylated and complexed with $\mathrm{p} 300 / \mathrm{CBP}$ to stimulate IFN $\alpha / \beta$ genes $(40,87,92)$. The mechanism by which TLR signaling activates IRF-3 is not completely understood. It has been reported that the DNA-dependent kinase contributes to the activation of IRF-3 (33), although other kinases may also play a role in the process.

\section{CYTOKINE GENE EXPRESSION AFTER TLR SIGNALING}

Following ligand-TLR binding, numerous genes are induced in both macrophages and dendritic cells, including many cytokines. Other genes involved in antimicrobial activities, including chemokines, proteolytic enzymes, and extracellular matrix, are also induced, along with genes important for antigen presentation, such as major histocompatibility complex class II and co-stimulatory molecules. This is well illustrated in a recent genome-wide microarray study (19) in which global gene expression patterns were investigated in a dendritic cell line following exposure to E. coli. Within 4-6 h, cytokines that regulate inflammatory responses (including IL-1 $\alpha$, IL-1RA, IL-2, IL-6, IL-10, IL-12p35, IL-12 p40, IL-15, and TNF $\alpha$ ) were induced. Other cytokines that affect cell growth/survival, such as VEGF, $\mathrm{M}-\mathrm{CSF}$, and GM-CSF, were also induced. It is likely that most if not all of these cytokines are downstream targets of TLR signaling, although formal proof is lacking. Other ligands such as CpG are known to induce a large array of cytokines $(38,91)$.

From these studies, it is clear that TLR signaling results in the expression of not only pro-inflammatory cytokines but also antiinflammatory cytokines such as IL-10 and IL-6, suggesting that balancing pro- and anti-inflammatory responses is part of TLR signaling and that this activity begins at an early stage of TLR response. Another aspect of note is the induction of IL-12 and IL10. These are cytokines that do not have antimicrobial activities by themselves. Their main activity is to regulate expression of ef fector cytokines, including IFN $\gamma$ and IL-4, thereby coordinating the innate responses with subsequent adaptive immune responses $(54,80)$. Thus, in mammals, the linking of the innate and adaptive immune responses is an integral part of TLR signaling. Al- though the basic TLR system is conserved from insects to vertebrates (37), this aspect may well represent a point of divergence.

\section{TYPE I IFNs (IFN $\alpha / \beta)$}

IFN $\alpha / \beta$ are a major mechanism of innate defense against viral infection, as these cytokines activate PKR, Mx, and RNaseL. IFN $\alpha / \beta$ are expressed through TLR signaling, involving TLR3, TLR9, and probably other TLRs. In humans, all 15 IFN genes are encoded in the IFN cluster in chromosome 9 (14). Although IFN $\beta$ can be expressed broadly in many types of cells, IFN $\alpha$ is produced predominantly by "leukocytes". Recently, dendritic cells have been identified as a single major cell type that produces IFN $\alpha$ in humans $(13,70)$. Plasmacytoid dendritic cells produce greater than 200-1000 times higher amounts of IFN $\alpha$ than other blood cells in response to viruses, dsRNA, and CpG DNA (30). Mouse pDCs also express high levels of $\operatorname{IFN} \alpha(3,18)$.

IRF-3, activated by dsRNA and viruses, plays an essential role in the transcription of IFN $\alpha / \beta$ genes $(40,67,87,92)$ IRF-3 is activated by LPS through TLR4 (35). Thus, TLR3 and TLR9 are anticipated to activate IRF-3. In line with the role for TLR3, expression of IFN $\alpha$ and IFN $\beta$ gene is diminished in TLR3-/macrophages stimulated by dsRNA (2). The dependence of IFN $\alpha / \beta$ on TLR signaling is also supported by the observation that imidazoquinolin (TLR7)-induction of IFN $\alpha$ requires MyD88 (22).

Among the many type I IFN genes, only IFN $\beta$ and IFN $\alpha 4$ are immediate-early genes that are directly activated by viruses $(45,48)$. Other IFN genes are induced secondarily by IFN $\beta$ and IFN $\alpha 4$ in a STAT1-dependent manner (48). It is interesting that while the IFN $\beta$ promoter has a $\kappa \mathrm{B}$ site (45), IFN $\alpha$ genes seem to lack a canonical $\kappa B$ element (44), suggesting that NFKB is dispensable for IFN $\alpha$ expression. IFN $\alpha$ genes contain a PRDI like element and "TG element", both resembling the ISRE, a binding site for IRF proteins (9). Induction of IFN $\beta$ genes requires assembly of many factors, including NF $\kappa B$ and IRFs, as well as histone acetylases, and is associated with alterations of local chromatin structure $(49,53)$.

\section{IL-1 AND TNF $\alpha$, TYPICAL PRO-INFLAMMATORY CYTOKINES}

IL-1 elicits inflammatory responses upon infection and injuries (15) by signaling through the TLR-MyD88 pathway (Figure 1) (34). Alternatively, IL-1 $\beta$ gene expression itself is under control of TLR signaling. The IL- $1 \beta$ promoter has a $\kappa \mathrm{B}$ site that is important for LPS induction of the gene (24). However, this site alone is not sufficient for the full activation of promoter activity. It requires an additional site, the IRF/PU.1 composite element on which IRF-8/ICSBP, IRF-4, and PU.1 assemble, leading to cooperative activation of IL- $\beta$ transcription (47). The mechanism by which TLR signaling triggers the activity of the composite element is not fully understood. Interestingly, similar elements assembling IRF-8/ICSBP and PU.1 are present in other genes activated by TLR signaling (see below).

TNF $\alpha$ is another potent pro-inflammatory cytokine induced by the TLR signaling. TNFo's powerful biological effects are at- 


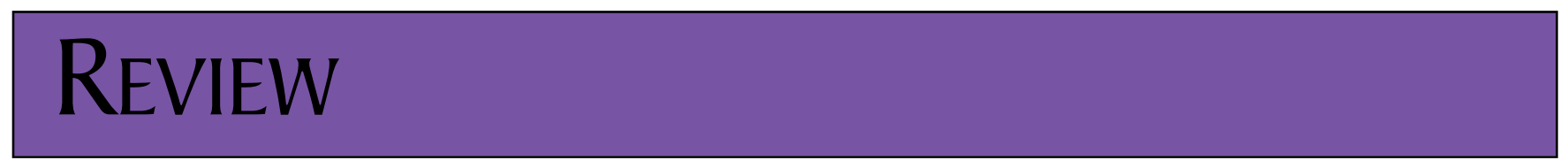

tributed to its ability to activate NFאB. LPS, CpG, and imidazoquinolin activate TNF $\alpha$ in a TLR- and MyD88-dependent manner $(22,23,34)$. The TNF $\alpha$ promoter has three NFKB binding sites, which function in a sequence-context and cell type-dependent manner. Unlike other cytokine promoters that require additional elements and other transcription factors, TNF $\alpha$ may require only NFKB for activation. Recent studies suggest that while the p $65-\mathrm{p} 50 \mathrm{\kappa B}$ heterodimer activates transcription, the p50 homodimer inhibits TNF $\alpha$ transcription (4). Interestingly, a naturally occurring variant of TNF $\alpha$ promoter has a $\kappa B$ site that preferentially binds to the $\mathrm{p} 50$ homodimer, attenuating TFN $\alpha$ expression (83).

\section{IL-10, A Th2 CYTOKINE}

IL-10 is an immunosuppressive cytokine produced in many cell types in response to LPS, mycobacteria, viruses, and TNF $\alpha$ (54). IL-10 down-regulates expression of IL-12 and IFN $\gamma$, there-

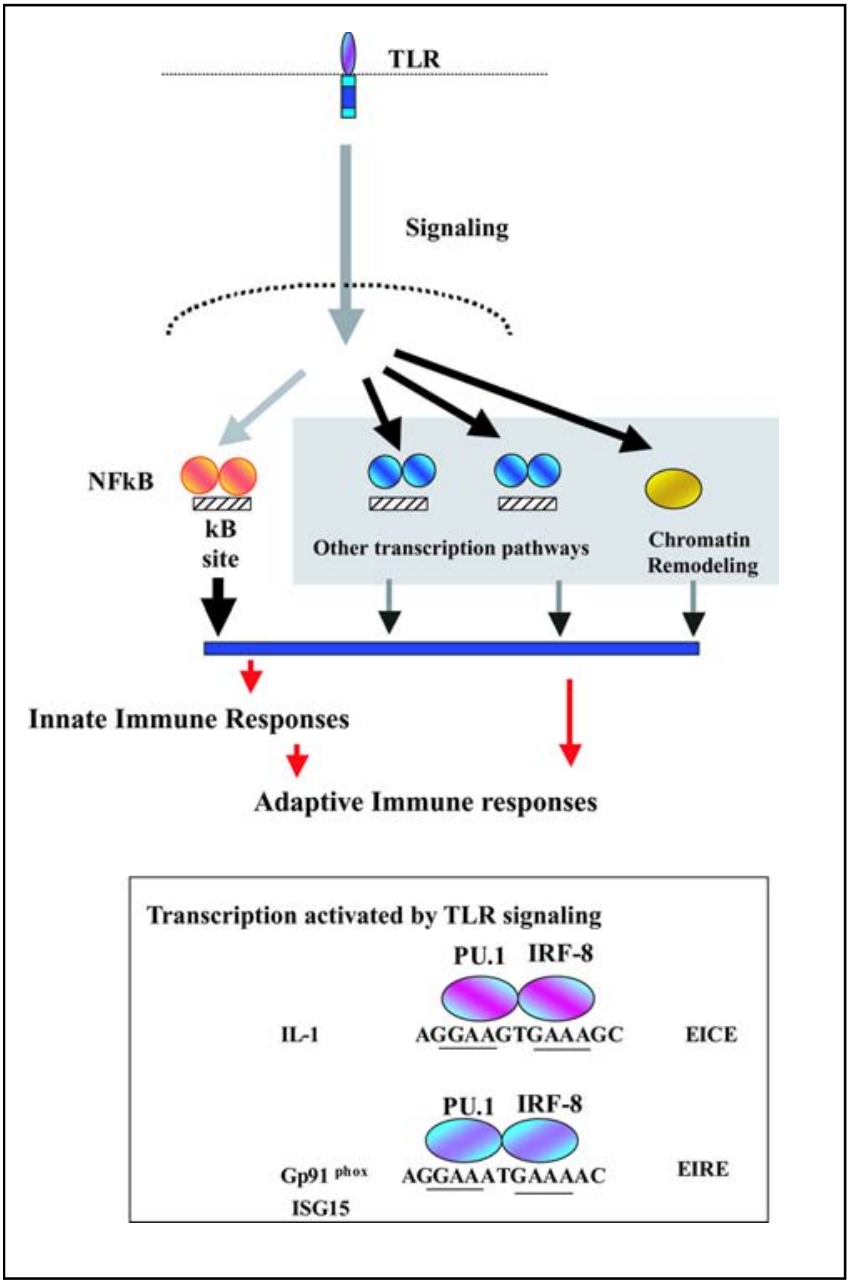

Figure 2. Gene activation after TLR signaling. (A) Complexity of TLR signaling in vertebrates. TLR signaling prompts chromatin remodeling and activation of multiple transcription factors (in addition to NFKB), initiating a mechanism to link innate and adaptive immunity. (B) TLR signaling stimulates IRF-8/ICSBP and PU.1 that cooperatively activate downstream genes with specific binding motifs. by inhibiting Th1 responses. The IL-10 promoter binds to Sp1 and $\mathrm{Sp} 3$, both of which regulate constitutive transcription (78). $\mathrm{Sp} 1$ is also shown to be involved in LPS activation of IL-10 promoter (11). In macrophages, LPS induction of IL-10 transcription requires new protein synthesis, indicating that induction depends on some other cofactors or modification of Sp1. IL-10 transcription may also be regulated at the level of mRNA stability (62). The IL-10 promoter is unusual in that it does not have a canonical $\kappa \mathrm{B}$ site. Details of the pathways by which TLR signals activate IL-10 gene expression await further investigation.

\section{IL-12, A Th1 CYTOKINE}

This cytokine is a key mediator of Th1 responses, as it induces expression of IFN $\gamma$ in NK and T cells (80). IL-12 is composed of a heterodimer of $\mathrm{p} 40$ and $\mathrm{p} 35 . \mathrm{p} 40$ is a highly inducible subunit and regulates the overall production of biologically active IL-12p70. Although previously thought to be constitutively expressed, the $\mathrm{p} 35$ subunit is also regulated by external stimuli (71). IL-12 is induced by bacteria, viruses, parasites in macrophages, and dendritic cells. Induction by CpG, dsRNA, and imidazoquinolin is dependent on TLR3, TLR4, TLR7, and TLR9, respectively, all of which require MyD88 (2,22,23,32).

Because of its central role in bridging innate and adaptive immune responses, IL-12 transcription has been extensively studied. IL-12 p40 is synergistically induced in macrophages by LPS and IFN $\gamma$, which requires new protein synthesis (43). IFN $\gamma$ also synergizes with $\mathrm{CpG}$ and imidazoquinolin to induce IL-12 p40 expression (22). We found that the mode of IL-12 induction in dendritic cells differs from that in macrophages, in that IL-12 p40 induction in dendritic cells does not require a new protein synthesis and does not depend on IFN $\gamma$ for full expression (Tsujimura et al., unpublished observations).

Contrary to IFN $\gamma$ 's stimulatory activity, relatively high doses of IFN $\alpha / \beta$ are shown to inhibit IL-12 induction in a variety of systems in both mouse and human (7). For example, IL-12 production in vivo is markedly reduced following infection with lymphocytic choriomeningitis virus. In addition, pretreatment of monocytes with IFN $\alpha$ or IFN $\beta$ also reduces IL-12 p40 expression in vitro. However, the mechanism by which IFN $\alpha / \beta$ inhibit IL12 expression is not well understood. Interestingly, LPS induction of IL-12 p40 in macrophages is dependent on p38 MAPK, as evidenced by the absence of IL-12 in Mkk3-/- mice, although induction of IL-1, TNF $\alpha$, and IL-6 is normal in these mice (42).

Activity of the IL-12 p 40 promoter has been studied in mouse $(60,89)$ as well as human $(20,43,86)$ and involves multiple regulatory elements, including the $\mathrm{\kappa B}, \mathrm{C} / \mathrm{EBP}$, and Ets sites. Consistent with the importance of the $\kappa \mathrm{B}$ site, disruption of c-Rel, a member of the NFKB family, selectively diminishes IL-12 p40 expression in macrophages, while p65-/- and p50-/- mice express the gene (66). However, the lack of c-Rel alone did not show a defect in expressing IL-12 p40 in dendritic cells (58). Thus, NFкB may play a differential role in macrophages and dendritic cells.

Although current information suggests that $\mathrm{NF}$ (B plays a critical role, there are other factors that regulate IL-12 p40 expression. We have obtained evidence that IRF-8/ICSBP is essential for the expression of IL-12 p40 $(69,75,82,86)$. IRF$8 / \mathrm{ICSBP}$ is synergistically induced by LPS and IFN $\gamma$ in 


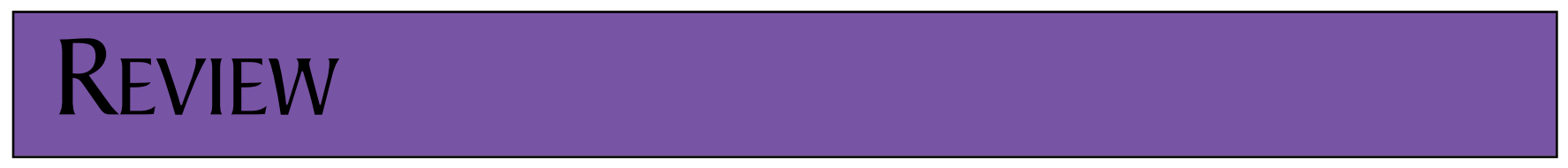

macrophages, but its expression is constitutive in dendritic cells $(76,82)$. IRF-8/ICSBP-/- macrophages and dendritic cells fail to express IL-12 p40 in response to IFN $\gamma+$ LPS and all other stimuli tested, although they express TLR4, TLR9, and MyD88 at normal levels (82). We showed that transfection of IRF-8/ICSBP into -/- cells restores expression of endogenous IL-12 p40 mRNA along with co-transfected mouse and human IL-12 p40 promoters (86). In addition, myeloid progenitor cells derived from IRF-8/ICSBP-/- cells, when IRF-8/ICSBP was reintroduced, acquired the ability to induce IL-12 p40 in response to LPS and IFN $\gamma$, along with the ability to differentiate into macrophages (75). Further analysis indicated that IRF-8/ICSBP is assembled into a multi-protein complex containing IRF-1, which binds to the IL-12 p40 promoter (86). A similar complex that contains PU.1, IRF-8, and c-Rel is shown to assemble on the human IL-12 promoter (20).

In vivo footprinting analysis of the mouse IL-12 p40 promoter by Weinmann et al. (89) demonstrated that upon LPS and IFN $\gamma$ stimulation the promoter undergoes a dramatic chromatin remodeling, most prominently in nucleosome 1 (adjacent to the transcription start site). Concomitant with the remodeling was a marked increase in restriction site accessibility in and around the nucleosome. This remodeling event was dependent on de novo protein synthesis. A more recent study (88) shows that the increased restriction site accessibility depends on TLR4, but not on NFKB, as c-Rel-/- macrophages undergo nucleosomal remodeling. These studies indicate that TLR-MyD88 signaling activates NFKB as well as another protein/pathway(s) important for IL-12 p40 transcription.

\section{TRANSCRIPTIONAL MECHANISMS BY WHICH TLRs ACTIVATE GENE EXPRESSION}

A major downstream target of TLR signaling is NFKB, a feature conserved throughout evolution. However, in mammalian species, transcription factors other than $\mathrm{NF \kappa B}$ are activated by TLR signaling and probably play a major role in gene expression. These transcription factors may be particularly indispensable for regulating genes that coordinate innate and adaptive immune responses. In this context, it is interesting that expression of major histocompatibility complex class II and co-stimulatory molecules, as well as elicitation of allogeneic mixed lymphocyte reaction, is not impaired in cells lacking both $\mathrm{NFKB}$ p 50 and cRel (58). This supports the hypothesis that NFKB is not required for certain TLR pathways, such as those linking innate and adaptive immune responses.

Other transcription factors that are expected to take part in TLR signaling in mammalian cells are proteins of the IRF family (77). Besides IRF-3, IRF-8/ICSBP is likely to have a significant role in TLR signaling. IRF-8/ICSBP is a key factor for induction of IL-12 p40, IL-1 $\beta$, gp91phox, and IL-18R (16,36,46, $47,64,86)$. In each of these promoters, IRF- 8 acts by interacting with PU.1, a member of the Ets family whose expression pattern parallels that of IRF-8/ICSBP. The two factors bind to the EtsIRF composite element (EICE) to stimulate transcription (Figure 2). The canonical EICE contains the Est consequence site (A)GGAA and a half IRF site GAAA (10). Although a canonical EICE is not present, the IL-12 p40 promoter is shown to assem- ble a complex containing PU.1 and IRF-8/ICSBP (20). Moreover, EICE-like elements (designated EIRE) are found to be present in some IFN-inducible genes (Figure 2). IRF-8/ICSBP and PU.1 are reported to stimulate transcription through this element (52). We have shown that IRF-8/ICSBP interacts with TEL, another Ets family protein, representing an additional possible mechanism of regulation (39).

Finally, it is likely that TLR signaling not only activates individual transcription factors but also mediates a large-scale alteration in chromatin structure, affecting global gene expression patterns. Indicative of a chromatin change, Saccani et al. (65) reported that many TLR ligands activate p38 MAP in human primary dendritic cells, which results in promoter-specific phosphorylation and acetylation of histone $\mathrm{H} 3$. This change is seen within $10 \mathrm{~min}$ after stimulation and probably involves recruitment of histone acetylases and other chromatin modifiers, leading to increased transcriptional activation of a series of genes. However, the specific nature of chromatin changes and mechanisms causing these changes are still largely unknown.

In conclusion, TLR signaling governs the expression of many cytokine genes in macrophages and dendritic cells, establishing innate immunity and opening a road to adaptive immune responses. Although NFKB is a factor critical for the conserved function of TLR signaling, additional transcription factors are expected to participate in the TLR signaling in vertebrates to link innate and adaptive immunity.

\section{REFERENCES}

1.Adachi, O., T. Kawai, K. Takeda, M. Matsumoto, H. Tsutsui, M. Sakaga mi, K. Nakanishi, and S. Akira. 1998. Targeted disruption of the MyD88 gene results in loss of IL-1- and IL-18-mediated function. Immunity 9:143150 .

2.Alexopoulou, L., A.C. Holt, R. Medzhitov, and R.A. Flavell. 2001. Recognition of double-stranded RNA and activation of NF- $\kappa$ B by Toll-like receptor 3. Nature 413:732-738.

3.Asselin-Paturel, C., A. Boonstra, M. Dalod, I. Durand, N. Yessaad, C. Dezutter-Dambuyant, A. Vicari, A. O’Garra, et al. 2001. Mouse type I IFN-producing cells are immature APCs with plasmacytoid morphology. Nat. Immunol. 2:1144-1150.

4.Baer, M., A. Dillner, R.C. Schwartz, C. Sedon, S. Nedospasov, and P.F. Johnson. 1998. Tumor necrosis factor $\alpha$ transcription in macrophages is attenuated by an autocrine factor that preferentially induces NF-KB p 50 . Mol. Cell Biol. 18:5678-5689.

5.Banchereau, J. and R.M. Steinman. 1998. Dendritic cells and the control of immunity. Nature 392:245-252.

6.Bauer, S., C.J. Kirschning, H. Hacker, V. Redecke, S. Hausmann, S. Akira H. Wagner, and G.B. Lipford. 2001. Human TLR9 confers responsiveness to bacterial DNA via species-specific CpG motif recognition. Proc. Natl. Acad. Sci. USA 98:9237-9242.

7.Biron, C.A. 2001. Interferons $\alpha$ and $\beta$ as immune regulators-a new look. Immunity 14:661-664.

8.Bosisio, D., N. Polentarutti, M. Sironi, S. Bernasconi, K. Miyake, G.R. Webb, M.U. Martin, A. Mantovani, and M. Muzio. 2002. Stimulation of toll-like receptor 4 expression in human mononuclear phagocytes by interferon- $\gamma$ : a molecular basis for priming and synergism with bacterial lipopolysaccharide. Blood 99:3427-3431.

9.Braganca, J. and A. Civas. 1998. Type I interferon gene expression: differential expression of IFN-A genes induced by viruses and double-stranded RNA. Biochimie 80:673-687.

10.Brass, A.L., E. Kehrli, C.F. Eisenbeis, U. Storb, and H. Singh. 1996. Pip, a lymphoid-restricted IRF, contains a regulatory domain that is important for autoinhibition and ternary complex formation with the Ets factor PU.1. Genes Dev. 10:2335-2347.

11.Brightbill, H.D., D.H. Libraty, S.R. Krutzik, R.B. Yang, J.T. Belisle, J.R. 


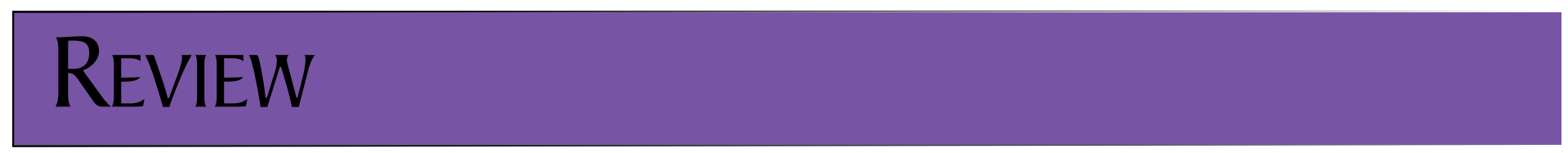

Bleharski, M. Maitland, M.V. Norgard, et al. 1999. Host defense mechanisms triggered by microbial lipoproteins through Toll-like receptors. Science 285:732-736

12.Cao, Z., J. Xiong, M. Takeuchi, T. Kurama, and D.V. Goeddel. 1996. TRAF6 is a signal transducer for interleukin-1. Nature 383:443-446.

13.Cella, M., D. Jarrossay, F. Facchetti, O. Alebardi, H. Nakajima, A. Lanzavecchia, and M. Colonna. 1999. Plasmacytoid monocytes migrate to inflamed lymph nodes and produce large amounts of type I interferon. Nat. Med. 5:919-923.

14.Diaz, M. and D. Testa. 1996. Type I interferon genes and proteins. Biotherapy $8: 157-162$.

15.Dinarello, C.A. 1994. The interleukin-1 family: 10 years of discovery. FASEB J. 8:1314-1325.

16. Eklund, E.A. and R. Kakar. 1999. Recruitment of CREB-binding protein by PU.1, IFN-regulatory factor-1, and the IFN consensus sequence-binding protein is necessary for IFN- $\gamma$-induced p67phox and gp91phox expression. J. Immunol. 163:6095-6105.

17.Fitzgerald, K.A., E.M. Palsson-McDermott, A.G. Bowie, C.A. Jefferies, A.S. Mansell, G. Brady, E. Brint, A. Dunne, et al. 2001. Mal (MyD88adapter-like) is required for Toll-like receptor-4 signal transduction. Nature 413:78-83.

18.Gilliet, M., A. Boonstra, C. Paturel, S. Antonenko, X.L. Xu, G. Trinchieri, A. O'Garra, and Y.J. Liu. 2002. The development of murine plasmacytoid dendritic cell precursors is differentially regulated by FLT3-ligand and granulocyte/macrophage colony-stimulating factor. J. Exp. Med. 195:953-958.

19.Granucci, F., C. Vizzardelli, N. Pavelka, S. Feau, M. Persico, E. Virzi, M. Rescigno, G. Moro, and P. Ricciardi-Castagnoli. 2001. Inducible IL-2 production by dendritic cells revealed by global gene expression analysis. Nat. Immunol. 2:882-888

20. Grazia Cappiello, M., F.S. Sutterwala, G. Trinchieri, D.M. Mosser, and X. Ma. 2001. Suppression of Il-12 transcription in macrophages following Fc gamma receptor ligation. J. Immunol. 166:4498-4506.

21.Hayashi, F., K.D. Smith, A. Ozinsky, T.R. Hawn, E.C. Yi, D.R. Goodlett, J.K. Eng, S. Akira, D.M. Underhill, and A. Aderem. 2001. The innate immune response to bacterial flagellin is mediated by Toll-like receptor 5 . Nature 410.1099-1103.

22.Hemmi, H., T. Kaisho, O. Takeuchi, S. Sato, H. Sanjo, K. Hoshino, T. Horiuchi, H. Tomizawa, K. Takeda, and S. Akira. 2002. Small anti-viral compounds activate immune cells via the TLR7 MyD88-dependent signaling pathway. Nat. Immunol. 3:196-200.

23.Hemmi, H., O. Takeuchi, T. Kawai, T. Kaisho, S. Sato, H. Sanjo, M. Matsumoto, K. Hoshino, et al. 2000. A Toll-like receptor recognizes bacterial DNA. Nature 408:740-745.

24. Hiscott, J., J. Marois, J. Garoufalis, M. D’Addario, A. Roulston, I. Kwan, N. Pepin, J. Lacoste, et al. 1993. Characterization of a functional NF-kB site in the human interleukin $1 \beta$ promoter: evidence for a positive autoregulatory loop. Mol. Cell Biol. 13:6231-6240.

25.Horng, T., G.M. Barton, and R. Medzhitov. 2001. TIRAP: an adapter molecule in the Toll signaling pathway. Nat. Immunol. 2:835-841.

26.Hornung, V., S. Rothenfusser, S. Britsch, A. Krug, B. Jahrsdorfer, T. Giese, S. Endres, and G. Hartmann. 2002. Quantitative expression of toll-like receptor 1-10 mRNA in cellular subsets of human peripheral blood mononuclear cells and sensitivity to $\mathrm{CpG}$ oligodeoxynucleotides. J. Immunol. 168:4531-4537.

27.Hoshino, K., O. Takeuchi, T. Kawai, H. Sanjo, T. Ogawa, Y. Takeda, K. Takeda, and S. Akira. 1999. Cutting edge: Toll-like receptor 4 (TLR4)-defi cient mice are hyporesponsive to lipopolysaccharide: evidence for TLR4 as the Lps gene product. J. Immunol. 162:3749-3752.

28. Janeway, C.A., Jr., and R. Medzhitov. 2002. Innate immune recognition. Annu. Rev. Immunol. 20:197-216.

29.Jurk, M., F. Heil, J. Vollmer, C. Schetter, A.M. Krieg, H. Wagner, G. Lipford, and S. Bauer. 2002. Human TLR7 or TLR8 independently confer responsiveness to the antiviral compound R-848. Nat. Immunol. 3:499.

30.Kadowaki, N., S. Ho, S. Antonenko, R.W. Malefyt, R.A. Kastelein, F. Bazan, and Y.J. Liu. 2001. Subsets of human dendritic cell precursors express different Toll-like receptors and respond to different microbial antigens. J. Exp. Med. 194:863-869.

31.Kaisho, T. and S. Akira. 2002. Toll-like receptors as adjuvant receptors. Biochim. Biophys. Acta 1589:1-13.

32.Kaisho, T., O. Takeuchi, T. Kawai, K. Hoshino, and S. Akira. 2001. Endotoxin-induced maturation of myd88-deficient dendritic cells. J. Immunol. 166.5688-5694
33.Karpova, A.Y., M. Trost, J.M. Murray, L.C. Cantley, and P.M. Howley 2002. Interferon regulatory factor-3 is an in vivo target of DNA-PK. Proc. Natl. Acad. Sci. USA 99:2818-2823.

34.Kawai, T., O. Adachi, T. Ogawa, K. Takeda, and S. Akira. 1999. Unresponsiveness of MyD88-deficient mice to endotoxin. Immunity 11:115-122.

35.Kawai, T., O. Takeuchi, T. Fujita, J. Inoue, P.F. Muhlradt, S. Sato, K Hoshino, and S. Akira. 2001. Lipopolysaccharide stimulates the MyD88-independent pathway and results in activation of IFN-regulatory factor 3 and the expression of a subset of lipopolysaccharide-inducible genes. J. Immunol. 167:5887-5894

36.Kim, Y.M., H.S. Kang, S.G. Paik, K.H. Pyun, K.L. Anderson, B.E. Torbett, and I. Choi. 1999. Roles of IFN consensus sequence binding protein and PU.1 in regulating IL-18 gene expression. J. Immunol. 163:2000-2007.

37. Kimbrell, D.A. and B. Beutler. 2001. The evolution and genetics of innate immunity. Nat. Rev. Genet. 2:256-267.

38. Krieg, A.M. 2002. CpG motifs in bacterial DNA and their immune effects. Annu. Rev. Immunol. 20:709-760.

39. Kuwata, T., C. Gongora, Y. Kanno, K. Sakaguchi, T. Tamura, T. Kanno, V. Basrur, R. Martinez, et al. Interferon- $\gamma$ triggers the interaction between ICS$\mathrm{BP}(\mathrm{IRF}-8)$ and TEL recruiting the histone deacetylase HDAC3 to the interferon responsive element. Mol. Cell Biol. (In Press.)

40.Lin, R., C. Heylbroeck, P.M. Pitha, and J. Hiscott. 1998. Virus-dependent phosphorylation of the IRF-3 transcription factor regulates nuclear translocation, transactivation potential, and proteasome-mediated degradation. Mol. Cell Biol. 18:2986-2996.

41.Lord, K.A., B. Hoffman-Liebermann, and D.A. Liebermann. 1990. Nucleotide sequence and expression of a cDNA encoding MyD88, a novel myeloid differentiation primary response gene induced by IL6. Oncogene 5:1095-1097.

42.Lu, H.T., D.D. Yang, M. Wysk, E. Gatti, I. Mellman, R.J. Davis, and R.A. Flavell. 1999. Defective IL-12 production in mitogen-activated protein (MAP) kinase kinase 3 (Mkk3)-deficient mice. EMBO J. 18:1845-1857.

43.Ma, X., J.M. Chow, G. Gri, G. Carra, F. Gerosa, S.F. Wolf, R. Dzialo, and G. Trinchieri. 1996. The interleukin $12 \mathrm{p} 40$ gene promoter is primed by interferon $\gamma$ in monocytic cells. J. Exp. Med. 183:147-157.

44. MacDonald, N.J., D. Kuhl, D. Maguire, D. Naf, P. Gallant, A. Goswamy, H. Hug, H. Bueler, et al. 1990. Different pathways mediate virus inducibility of the human IFN- $\alpha 1$ and IFN- $\beta$ genes. Cell 60:767-779.

45.Maniatis, T., J.V. Falvo, T.H. Kim, T.K. Kim, C.H. Lin, B.S. Parekh, and M.G. Wathelet. 1998. Structure and function of the interferon- $\beta$ enhanceosome. Cold Spring Harb. Symp. Quant. Biol. 63:609-620.

46.Marecki, S. and M.J. Fenton. 2000. PU.1/interferon regulatory factor interactions: mechanisms of transcriptional regulation. Cell. Biochem. Biophys. 33:127-148

47.Marecki, S., C.J. Riendeau, M.D. Liang, and M.J. Fenton. 2001. PU.1 and multiple IFN regulatory factor proteins synergize to mediate transcriptional activation of the human IL-1 $\beta$ gene. J. Immunol. 166.6829-6838.

48. Marie, I., J.E. Durbin, and D.E. Levy. 1998. Differential viral induction of distinct interferon- $\alpha$ genes by positive feedback through interferon regulatory factor-7. EMBO J. 17:6660-6669.

49.Masumi, A. and K. Ozato. 2001. Coactivator p300 acetylates the interferon regulatory factor-2 in U937 cells following phorbol ester treatment. J. Biol. Chem. 276:20973-20980.

50.Matsumoto, M., S. Kikkawa, M. Kohase, K. Miyake, and T. Seya. 2002. Establishment of a monoclonal antibody against human Toll-like receptor 3 that blocks double-stranded RNA-mediated signaling. Biochem. Biophys. Res. Commun. 293:1364-1369.

51.Medvedev, A.E., K.M. Kopydlowski, and S.N. Vogel. 2000. Inhibition of lipopolysaccharide-induced signal transduction in endotoxin-tolerized mouse macrophages: dysregulation of cytokine, chemokine, and Toll-like receptor 2 and 4 gene expression. J. Immunol. 164:5564-5574.

52.Meraro, D., M. Gleit-Kielmanowicz, H. Hauser, and B.Z. Levi. 2002 IFN-stimulated gene 15 is synergistically activated through interactions between the myelocyte/lymphocyte-specific transcription factors, PU.1, IFN regulatory factor-8/IFN consensus sequence binding protein, and IFN regulatory factor-4. J. Immunol. 168:6224-6231.

53.Merika, M., A. J. Williams, G. Chen, T. Collins, and D. Thanos. 1998. Recruitment of $\mathrm{CBP} / \mathrm{p} 300$ by the IFN $\beta$ enhanceosome is required for synergistic activation of transcription. Mol. Cell. 1:277-287.

54.Moore, K.W., R. de Waal Malefyt, R.L. Coffman, and A. O'Garra. 2001. Interleukin-10 and the interleukin-10 receptor. Annu. Rev. Immunol. 19:683-765. 
55.Muzio, M., D. Bosisio, N. Polentarutti, G. D'Amico, A. Stoppacciaro, R. Mancinelli, C. van't Veer, G. Penton-Rol, et al. 2000. Differential expression and regulation of Toll-like receptors (TLR) in human leukocytes: selective expression of TLR3 in dendritic cells. J. Immunol. 164:5998-6004.

56.Ninomiya-Tsuji, J., K. Kishimoto, A. Hiyama, J. Inoue, Z. Cao, and K. Matsumoto. 1999. The kinase TAK1 can activate the NIK-I $\kappa B$ as well as the MAP kinase cascade in the IL-1 signalling pathway. Nature 398:252-256.

57.O'Neill, L.A. 2000. The interleukil receptor/Toll-like receptor superfamily: signal transduction during inflammation and host defense. Sciene Stke. 44:1-11.

58. Ouaaz, F., J. Arron, Y. Zheng, Y. Choi, and A.A. Beg. 2002. Dendritic cell development and survival require distinct NF- $\mathrm{\kappa B}$ subunits. Immunity 16:257-270.

59.Ozinsky, A., D.M. Underhill, J.D. Fontenot, A.M. Hajjar, K.D. Smith, C.B. Wilson, L. Schroeder, and A. Aderem. 2000. The repertoire for pattern recognition of pathogens by the innate immune system is defined by cooperation between Toll-like receptors. Proc. Natl. Acad. Sci. USA 97:1376613771.

60.Plevy, S.E., J.H. Gemberling, S. Hsu, A.J. Dorner, and S.T. Smale. 1997. Multiple control elements mediate activation of the murine and human interleukin $12 \mathrm{p} 40$ promoters: evidence of functional synergy between C/EBP and Rel proteins. Mol. Cell Biol. 17:4572-4588.

61.Poltorak, A., X. He, I. Smirnova, M.Y. Liu, C.V. Huffel, X. Du, D. Birdwell, E. Alejos, et al. 1998. Defective LPS signaling in C3H/HeJ and C57BL/10ScCr mice: mutations in Tlr4 gene. Science 282:2085-2088.

62.Powell, M.J., S.A. Thompson, Y. Tone, H. Waldmann, and M. Tone. 2000. Posttranscriptional regulation of IL-10 gene expression through sequences in the 3'-untranslated region. J. Immunol. 165:292-296.

63.Qureshi, S.T., L. Lariviere, G. Leveque, S. Clermont, K.J. Moore, P. Gros, and D. Malo. 1999. Endotoxin-tolerant mice have mutations in Toll-like receptor 4 (Tlr4). J. Exp. Med. 189:615-625.

64. Rehli, M., A. Poltorak, L. Schwarzfischer, S.W. Krause, R. Andreesen, and B. Beutler. 2000. PU.1 and interferon consensus sequence-binding protein regulate the myeloid expression of the human Toll-like receptor 4 gene. J. Biol. Chem. 275:9773-9781.

65.Saccani, S., S. Pantano, and G. Natoli. 2002. p38-dependent marking of inflammatory genes for increased NF-KB recruitment. Nat. Immunol. 3:6975.

66.Sanjabi, S., A. Hoffmann, H.C. Liou, D. Baltimore, and S.T. Smale. 2000. Selective requirement for c-Rel during IL-12 P40 gene induction in macrophages. Proc. Natl. Acad. Sci. USA 97:12705-12710.

67.Sato, M., H. Suemori, N. Hata, M. Asagiri, K. Ogasawara, K. Nakao, T. Nakaya, M. Katsuki, et al. 2000. Distinct and essential roles of transcription factors IRF-3 and IRF-7 in response to viruses for IFN- $\alpha / \beta$ gene induction. Immunity 13:539-548.

68.Sato, S., F. Nomura, T. Kawai, O. Takeuchi, P.F. Muhlradt, K. Takeda, and S. Akira. 2000. Synergy and cross-tolerance between toll-like receptor (TLR) 2- and TLR4-mediated signaling pathways. J. Immunol. 165:7096-7101.

69.Scharton-Kersten, T., C. Contursi, A. Masumi, A. Sher, and K. Ozato. 1997. Interferon consensus sequence binding protein-deficient mice display impaired resistance to intracellular infection due to a primary defect in interleukin 12 p40 induction. J. Exp. Med. 186.1523-1534.

70.Siegal, F.P., N. Kadowaki, M. Shodell, P.A. Fitzgerald-Bocarsly, K. Shah, S. Ho, S. Antonenko, and Y.J. Liu. 1999. The nature of the principal type 1 interferon-producing cells in human blood. Science 284:1835-1837.

71.Snijders, A., C.M. Hilkens, T.C. van der Pouw Kraan, M. Engel, L.A. Aarden, and M.L. Kapsenberg. 1996. Regulation of bioactive IL-12 production in lipopolysaccharide- stimulated human monocytes is determined by the expression of the p35 subunit. J. Immunol. 156:1207-1212.

72.Sweet, M.J., K.J. Stacey, D.K. Kakuda, D. Markovich, and D.A. Hume. 1998. IFN- $\gamma$ primes macrophage responses to bacterial DNA. J. Interferon Cytokine Res. 18:263-271.

73. Takeuchi, O., K. Hoshino, T. Kawai, H. Sanjo, H. Takada, T. Ogawa, K. Takeda, and S. Akira. 1999. Differential roles of TLR2 and TLR4 in recognition of Gram-negative and Gram-positive bacterial cell wall components. Immunity 11:443-451.

74. Takeuchi, O., S. Sato, T. Horiuchi, K. Hoshino, K. Takeda, Z. Dong, R.L. Modlin, and S. Akira. 2002. Cutting edge: role of Toll-like receptor 1 in mediating immune response to microbial lipoproteins. J. Immunol. 169:10-14.

75. Tamura, T., T. Nagamura-Inoue, Z. Shmeltzer, T. Kuwata, and K. Ozato. 2000. ICSBP directs bipotential myeloid progenitor cells to differentiate into mature macrophages. Immunity 13:155-165.
76. Tamura, T. and K. Ozato. 2002. ICSBP/IRF-8: its regulatory roles in the development of myeloid cells. J. Interferon Cytokine Res. 22:145-152.

77. Taniguchi, T., K. Ogasawara, A. Takaoka, and N. Tanaka. 2001. IRF family of transcription factors as regulators of host defense. Annu. Rev. Immunol. 19.623-655.

78. Tone, M., M.J. Powell, Y. Tone, S.A. Thompson, and H. Waldmann. 2000. IL-10 gene expression is controlled by the transcription factors Sp1 and Sp3. J. Immunol. 165:286-291.

79. Toshchakov, V., B.W. Jones, P.Y. Perera, K. Thomas, M.J. Cody, S. Zhang, B.R. Williams, J. Major, et al. 2002. TLR4, but not TLR2, mediates IFN- $\beta$ induced STAT $1 \alpha / \beta$-dependent gene expression in macrophages. Nat. Immunol. 3:392-398

80.Trinchieri, G. 1998. Interleukin-12: a cytokine at the interface of inflammation and immunity. Adv. Immunol. 70:83-243.

81. Tsujimura, H., T. Nagamura-Inoue, T. Tamura, and K. Ozato. 2002. ICSBP/IRF-8 guides bone marrow progenitor cells to differentiate towards the macrophage lineage. J. Immunol. 169:1261-1269.

82.Tsujimura, H., T. Tamura, C. Gongora, J. Aliberti, C. Reis e Sausa, A. Sher, and K. Ozato. ICSBP/IRF-8 retrovirus transduction rescues dendritic cell development in vitro. Blood (In press.)

83.Udalova, I.A., A. Richardson, A. Denys, C. Smith, H. Ackerman, B. Foxwell, and D. Kwiatkowski. 2000. Functional consequences of a polymorphism affecting NF- $\mathrm{KB} \mathrm{p} 50-\mathrm{p} 50$ binding to the TNF promoter region. Mol. Cell Biol. 20:9113-9119.

84.Underhill, D.M., A. Ozinsky, A.M. Hajjar, A. Stevens, C.B. Wilson, M. Bassetti, and A. Aderem. 1999. The Toll-like receptor 2 is recruited to macrophage phagosomes and discriminates between pathogens. Nature 401:811-815.

85.Visintin, A., A. Mazzoni, J.H. Spitzer, D.H. Wyllie, S.K. Dower, and D.M. Segal. 2001. Regulation of Toll-like receptors in human monocytes and dendritic cells. J. Immunol. 166:249-255.

86. Wang, I.M., C. Contursi, A. Masumi, X. Ma, G. Trinchieri, and K. Ozato. 2000. An IFN- $\gamma$-inducible transcription factor, IFN consensus sequence binding protein (ICSBP), stimulates IL-12 p40 expression in macrophages. J. Immunol. 165:271-279.

87.Weaver, B.K., K.P. Kumar, and N.C. Reich. 1998. Interferon regulatory factor 3 and CREB-binding protein/p300 are subunits of double-stranded RNA-activated transcription factor DRAF1. Mol. Cell Biol. 18:1359-1368.

88. Weinmann, A.S., D.M. Mitchell, S. Sanjabi, M.N. Bradley, A. Hoffmann, H.C. Liou, and S.T. Smale. 2001. Nucleosome remodeling at the IL-12 p40 promoter is a TLR-dependent, Rel-independent event. Nat. Immunol. 2:5157.

89. Weinmann, A.S., S.E. Plevy, and S.T. Smale. 1999. Rapid and selective remodeling of a positioned nucleosome during the induction of IL-12 p40 transcription. Immunity 11:665-675.

90.Wesche, H., W.J. Henzel, W. Shillinglaw, S. Li, and Z. Cao. 1997. MyD88 an adapter that recruits IRAK to the IL-1 receptor complex. Immunity 7:837-847.

91.Yi, A.K., J.G. Yoon, S.J. Yeo, S.C. Hong, B.K. English, and A.M. Krieg. 2002. Role of mitogen-activated protein kinases in CpG DNA-mediated IL10 and IL-12 production: central role of extracellular signal-regulated kinase in the negative feedback loop of the CpG DNA-mediated Th1 response. J. Immunol. 168:4711-4720.

92. Yoneyama, M., W. Suhara, Y. Fukuhara, M. Fukuda, E. Nishida, and T. Fujita. 1998. Direct triggering of the type I interferon system by virus infection: activation of a transcription factor complex containing IRF-3 and CBP/p300. EMBO J. 17:1087-1095.

93.Zhang, G. and S. Ghosh. 2002. Negative regulation of toll-like receptor-mediated signaling by Tollip. J. Biol. Chem. 277:7059-7065.

\section{Address correspondence to:}

Dr. Keiko Ozato

Bldg 6, Rm 2AOI

Laboratory of Molecular Growth Regulation

NICHD, National Institutes of Health 6

Center Drive MSC-2753

Bethesda, MD 20892-2753, USA

e-mail: ozatok@nih.gov 